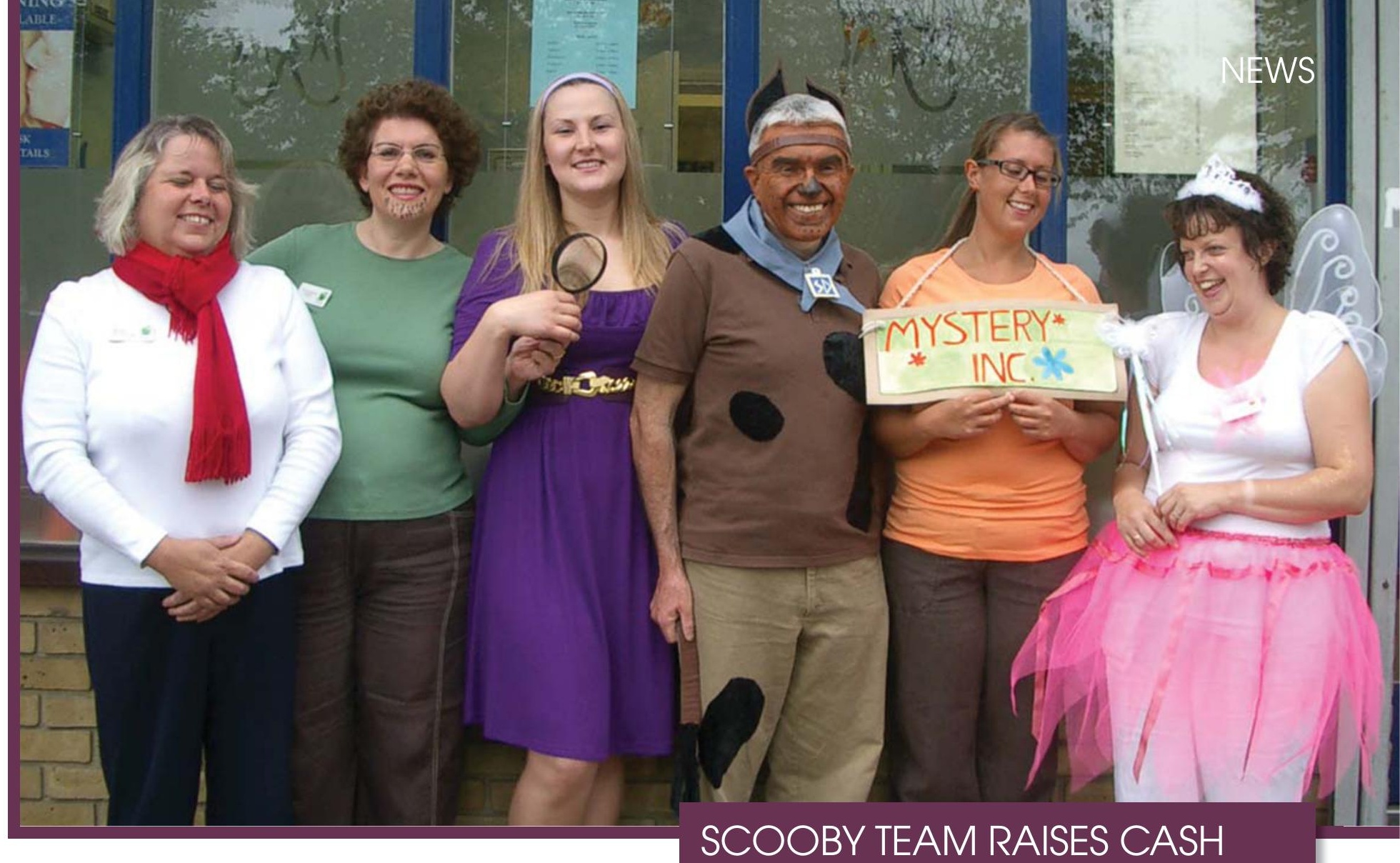

\section{ONE YEAR ANNIVERSARY FOR COMPULSORY REGISTRATION}

The General Dental Council recently marked the first anniversary of compulsory registration for dental nurses and dental technicians in the UK. It said that there were almost 44,500 dental nurses on its register and over 7,500 dental technicians.

Compulsory registration means that all members of the dental team are signed up to the same high standards that are implemented and regulated by the GDC. One year on around 47,000 of those who joined its registers before 31 July last year are preparing to submit their first returns of their five year cycle of continuing professional development (CPD). CPD ensures professionals are keeping their knowledge and skills up-to-date.

\section{STUDENT}

\section{TECHNICIAN}

\section{WINS AWARD}

Chetan Geisel has been awarded the British Orthodontic Society's Student Technician Award for 2009. Chetan received his award at the Orthodontic Technicians Association's Annual Conference in Milton Keynes from David Bearn, Chairman of the BOS Scholarship \& Grants Committee.

Entrants for the award were required to prepare two removable appliances to a given prescription along with a written commentary on the rationale for the designs. David Bearn, one of the judges, commented 'Chetan's entries were outstanding pieces of work showing that the skill of the orthodontic technician is alive and well'.
Staff at the Dartford Road Dental Centre took part in an annual Dress Up Day for dental charity Dentaid to raise funds for much needed dental and oral health care in the developing world by turning the Dental Centre into a Mystery Inc Scooby Doo set. 